\title{
Cabecinhas, Rosa (2007). Preto e Branco - A naturalização da discriminação racial. Porto: Campo das Letras
}

Carla Cerqueira

O livro Preto e Branco - A naturalização da discriminação racial resulta da tese de doutoramento de Rosa Cabecinhas, docente e investigadora do departamento de Ciências da Comunicação da Universidade do Minho. A obra, premiada em 2004 pelo Alto Comissariado para a Imigração e Minorias Étnicas, vem colmatar uma lacuna no conhecimento do racismo que, como refere Lígia Amâncio no prefácio do livro, "é um tema quase ausente do debate público em Portugal”. Pouco questionamos a relação entre nós e os outros, num país marcado pela emigração, mas que também se tem vindo a tornar um destino para muitos povos, sobretudo de África e de Leste.

Rosa Cabecinhas estudou o fenómeno da discriminação racial e étnica, evidenciando o contributo da Psicologia Social no entendimento da problemática, mas sem relegar a importância de outras áreas das Ciências Sociais. Aliás, a autora mostra bem, através desta reflexão teórica e empírica, o papel dos cientistas sociais no questionamento de certos fenómenos, com vista à construção de uma sociedade mais igualitária.

O projecto iniciou-se em 1997, Ano Europeu contra o Racismo, o qual foi marcado pelo lançamento da temática no espaço público, quer pelos agentes políticos, quer pelos actores mediáticos. Porém, os resultados mostram que a problemática do racismo é complexa e por isso, necessita de maior reflexão, pois nós continuamos a encontrar justificações para a exclusão social dos outros, quer sejam elas biológicas ou culturais (p. 21). A noção de 'raça' como conceito para classificar os seres humanos está desacreditada desde há largas décadas pelo discurso político e científico, mas esta persiste na memória colectiva, sendo reproduzida de forma "inconsciente e naturalizada" (Amâncio, p. 9), continuando a estruturar o pensamento do senso comum.

"Aprofundar o conhecimento dos processos cognitivos subjacentes à discriminação social, baseada na cor da pele ou da nacionalidade" (p. 14) é o objectivo desta investigação. A sua estrutura está organizada em seis capítulos, sendo que estes podem ser divididos em duas partes: os primeiros três capítulos contextualizam a problemática da investigação, ressaltam os objectivos, as hipóteses de pesquisa e explicam a metodologia adoptada; os restantes centram-se na análise e balanço empírico.

A autora apresenta um enquadramento teórico que atravessa as várias perspectivas interdisciplinares que têm contribuído para perceber como se opera a diferenciação entre nós e os outros, de forma a clarificar os conceitos centrais dentro desta temática de análise. Em paralelo, salienta a particularidade da sociedade portuguesa, marcada por um longo período ditatorial, em que o colonialismo foi bem marcante, mas no qual o enfoque recente se centra na recepção de imigrantes (Villaverde Cabral, 1997). Na construção do seu quadro teórico e para explicar os enviesamentos que ocorrem na percepção dos grupos sociais, enfatiza a insuficiência dos modelos puramente cognitivos e realça a importância do contexto histórico e social (p. 136). 
A investigação de Rosa Cabecinhas não se limita à utilização de um determinado tipo de procedimentos metodológicos, mas opta pelo confronto de diversos tipos de técnicas de recolha e tratamento de dados, com o objectivo de assegurar os resultados. Este rigor metodológico permite-lhe questionar a "universalidade" de determinados enviesamentos cognitivos. Opta, assim, pela junção de medidas directas (que permitem que as pessoas possam responder no sentido do 'socialmente correcto') e medidas implícitas (que permitem o acesso aos processos automáticos de processamento de informação sobre os grupos subjacentes) (p. 144).

Os últimos três capítulos do livro são dedicados à investigação empírica. A autora inicia com os estudos exploratórios que visam compreender quais são os grupos raciais ou étnicos mais relevantes na sociedade portuguesa e de que forma é que estes são percepcionados. Os resultados permitem-lhe a selecção de dois grupos com o mesmo grau de generalidade para os estudos posteriores: jovem estudantes portugueses e angolanos residentes em Portugal. As investigações anteriores tinham-se centrado no agente da discriminação, mas este estudo mostra-se pioneiro, pois vai além do grupo dominante. A autora centraliza a análise na perspectiva "dos membros de grupos que ocupam posições assimétricas na estrutura da sociedade” (p. 146). Uma opção que permite compreender também a percepção do alvo da discriminação, muitas vezes relegada para segundo plano.

O estudo revela que os estudantes nunca tinham problematizado as noções de raça e de grupo étnico, "considerando-as como conceitos objectivos explicativos das assimetrias sociais" (p. 270). Em consequência, aponta-se para a "naturalização" das categorias raciais (que são consideradas imutáveis) e étnicas (que são transitórias). Além disso, através dos dados empíricos chega-se à conclusão de que há uma centralidade da cor da pele na categorização dos grupos sociais. Portanto, e tal como outros investigadores anotam (Ferin, 2003a), o conceito de imigrante ou estrangeiro continua a estar, enganadoramente, colado à cor da pele.

Através dos estudos de estereótipos, a investigadora conclui que a diferenciação entre portugueses e angolanos opera-se quando se tem como referencial o modelo de pessoa 'adulta'. Assim, nós somos conotados com os valores ligados à instrumentalidade, enquanto os outros surgem associados ao estereótipo de pessoa 'jovem'. Estas questões perpassam a sociedade portuguesa, pois um estudo de Isabel Ferin (2003b) sobre Nós e os Outros nos artigos de opinião da imprensa portuguesa também mostra que os africanos aparecem frequentemente representados como exóticos.

Rosa Cabecinhas recorre também aos estudos experimentais que lhe indicam que os membros dos dois grupos estruturam a informação a partir da pertença racial ou étnica das pessoas-estímulo. Neste sentido, os elementos do grupo dominado são mais homogeneizados do que as pessoas do grupo dominante, independentemente do grupo de pertença dos observadores.

Por fim, a investigadora apresenta um estudo co-relacional, que tem como intuito comparar as percepções que os portugueses têm de vários grupos de origem africana angolanos, cabo-verdianos, guineenses, moçambicanos, são-tomenses e imigrantes negros 
no geral. Os dados mostram que não existe uma percepção diferenciada e que a categorização racial activa mais facilmente a norma anti-racismo do que a categorização nacional, ou seja, verifica-se um menor nível de discriminação face ao grupo dos negros (p. 250).

Podemos, assim, concluir que o racismo actual manifesta-se pelo não-reconhecimento da singularidade do outro, ou seja, pela percepção da homogeneidade do grupo dominado. Portanto, os outros são invisíveis enquanto pessoas, mas muito visíveis enquanto grupo. Contrariamente, nós somos personalizados e a nossa distintividade assume-se como central no seio do colectivo (p. 274).

Este trabalho tem, assim, o mérito de demonstrar que "não existe uma relação linear entre o efeito de homogeneidade do exogrupo e o favoritismo endogrupal, mas que esta relação é regulada pelo estatuto relativo dos grupos em presença e pelas suas estratégias de 'diferenciação positiva'” (p. 280). Esta conclusão assenta no "modelo da assimetria simbólica” (Amâncio, 1994), em que o grupo dominado acentua os estereótipos que salientam a pertença grupal, enquanto o grupo dominante realça os estereótipos que apontam para a personalização dos seus membros. Quer isto dizer que o tratamento da informação sobre os outros baseia-se nos estereótipos sociais, mas quando falamos de nós acentuam-se os traços contra-estereotípicos.

Nas considerações finais do trabalho, Rosa Cabecinhas salienta que o racismo não desapareceu, mas sofreu uma transformação e complexificou-se. Actualmente, nas sociedades ocidentais, formalmente anti-racistas, "assiste-se à permanência de fenómenos racistas, mas estes são cada vez menos justificados pela percepção de diferenças genéticas (raciais) e cada vez mais pela percepção de diferenças culturais ou religiosas (étnicas)" (p. 279). Sendo assim, as expressões de racismo surgem quase sempre "mascaradas e dissimuladas".

A autora segue a tese defendida por Vala (1999a: 7), que refere que o fenómeno do racismo não pode ser reduzido às suas "manifestações visíveis e identificáveis". Estamos, portanto, a falar de um racismo cada vez mais subtil, ou seja, de um fenómeno “difuso e velado". Em Portugal, o racismo só começou a ser estudado recentemente, mas as investigações existentes corroboram esta ideia de complexidade do fenómeno, que muitas vezes aparece mascarado pelo 'socialmente correcto', pelas normas de uma sociedade tolerante, não discriminatória e multicultural.

Em suma, esta obra é uma referência fundamental para quem se interessa pela reprodução de estereótipos e mecanismos de discriminação social, e nela pode ser traçado um paralelismo entre a discriminação racial e a discriminação sexual. Neste mundo dito civilizado, esta investigação empírica mostra-nos o olhar de quem domina e de quem é dominado e permite-nos perceber a subtileza do processo de categorização do exogrupo que aponta para o reforço de diferenças culturais (Vala, 1999b). O estatuto social dos grupos aparece como a palavra-chave, o que nos leva a acentuar o facto de que a maioria das pessoas faz parte de vários grupos em simultâneo, podendo passar de agente a alvo de discriminação. Além disso, pode existir um condicionalismo múltiplo, pois algumas pessoas fazem parte de vários grupos dominados em simultâneo. Esta perspectiva abre caminho a futuras investigações... 


\section{Referências bibliográficas}

Amâncio, Lígia (1994). Masculino e Feminino - A construção social da diferença. Porto: Afrontamento.

Cabral, Manuel Villaverde (1997). “Os portugueses são ou não racistas?”, em Crónicas Realistas: Sociedade e política em Portugal nos anos 90, Oeiras: Celta Editora, pp. 149-151.

Ferin, Isabel (2003a). Imigração e Racismo: 10 anos nos media. [Em linha] URL: http://www.bocc.ubi.pt [acedido em 15-03-2008].

Ferin, Isabel (2003b). Nós e os Outros nos Artigos de Opinião da Imprensa Portuguesa. [Em linha] URL: http://www.bocc.ubi.pt [acedido em 11-03-2008].

Vala, Jorge (1999a). Novos Racismos: Perspectivas comparativas, Oeiras: Celta Editora.

Vala, J., Brito, R. e Lopes, D. (1999b). Expressões dos Racismos em Portugal. Lisboa: Imprensa de Ciências Sociais. 